\title{
ACCOUNTABILITY OF JAPANESE CONSTRUCTION INDUSTRY
}

\author{
Takashi Kaneta ${ }^{1}$, Masaaki Kanoh ${ }^{2}$, Shuzo Furusaka ${ }^{1}$, Kouji Ichikawa ${ }^{3}$, Toshimasa \\ Okuma $^{4}$, Kenji Kimoto ${ }^{5}$, Shigehide Sakurai ${ }^{6}$, Ichiro Nakaoka ${ }^{7}$, Jea Sauk Lee ${ }^{8}$ \\ ${ }^{1}$ Dept. of Architecture and Architectural Systems, Kyoto University, Dr. Eng., ${ }^{2}$ Hanshin Electric Railway Co., \\ Ltd., ${ }^{3}$ Takenaka Research \& Development Institute, M. Eng., ${ }^{4}$ Building Construction Technology Division, \\ Kajima Corp., ${ }^{5}$ Research Institute of Technology, Konoike Construction, M. S., ${ }^{6}$ Kumagai Gumi, ${ }^{7}$ Central \\ Research Laboratory, Daiwa House Industry Co., Ltd., ${ }^{8}$ Dept. of Architecture, The University of Tokyo, M. Eng.
}

\begin{abstract}
This research aims to promote accountability in Japanese system of project management including the phases of architectural design and building construction. In introducing automation or robotics into construction industry, Japanese system is often regarded as characteristic one that cannot be accommodated to the systems of foreign countries. It is sometimes taken up as the difference between the local standard and the global standard. Japanese system, however, has many characters in common with other systems as well as the difference based on its culture and custom. This paper surveyed and reported the issues that show typical character of Japanese system in the field of project management.
\end{abstract}

Keywords: accountability, construction industry, building system, procurement, general contractor, contract.

\section{INTRODUCTION}

\subsection{Background}

Japanese economy receives a big turning point by a rapid recession. A past procurement method is reviewed so as to introduce $\mathrm{PM} / \mathrm{CM}$ (Project Management/ Construction Management) into Japanese construction market. The research and practice of $\mathrm{PM} / \mathrm{CM}$ have come to be spread widely because this procurement method is assumed to confirm the responsibility and the transparency of the cost. As PM/CM is originated in Europe and North America, it is quite easy to explain its system to foreign customers. The contract concerning $\mathrm{PM} / \mathrm{CM}$ is based on the documentation policy, so the responsibilities and roles of the owner, the designer, and the general contractor are defined clearly. The $\mathrm{PM} / \mathrm{CM}$ has settled in the contract society or the "lawsuit society", which made PM/CM equipped with high accountability. In other words, they lost trust to the traditional procurement method in Japanese construction industry.

In Japanese construction industry, efficiency is valued so that the competition has been excluded. Owners have not been able to claim the accountability of the procurement system because of the long-term, absolute mutual trust. Trying to protect Japanese market from opening to foreign firms, they often insisted the "uniqueness" of Japanese construction industry that originated in a peculiar history, the culture, and the climate.

However, it is obvious that traditional vague system is no longer effective in the era of international exchange and information technology. New technologies such as robotics are sometimes neglected because of the traditional customs of the firms. It is now important to promote accountability more widely to explain their service and value, the business finance, and the scope of the management. This is a way to get the trust and satisfaction from customers.

\subsection{Purpose of the research}

Based on such a background, this research aimed to show the advantage and disadvantage of the procurement system of Japanese construction industry. In order to make it clear to foreign customers, the framework of the facts found in real projects will be introduced logically about the Japanese system. Especially, the characteristics of general contractors are the first category to be made accountable in this paper as it is a fundamental problem in introducing robotics into construction projects.

\subsection{Scope of the research}

Since design-bid-build method is applied most in building construction projects in Japan, there are 
many examples that show the business manner and the role of general contractors. So in this paper the facts that are found in design-bid-build projects are targeted. It is often pointed that the competing power such as the ability of management and the quality of technology is not sufficiently evaluated among the enterprises in traditional system. In the shrinking construction market, the intensification of the competition is assumed to be a necessary method for the general contractors to get the moderate profit.

\subsection{Problems around the general contractors}

The general contractors are suffering from the increase of the cost by the indirect departments such as the research and development institute. This used to be no problem under the expansion of the market without the competition in later 80's. But now it is turned into so serious stage that even large firms among the general contractors go bankrupt because of the heavy financial debt in their balance sheet. Now the general contractors have recently altered their policy to obtain the value to service in such a situation. Naturally, accountability of their service is demanded. The reason why their profit has decreased is not only the shrink of the amount of construction market but also the profit structure of the general contractor had been weak. In other words, the customers had not understood the existence value of the general contractor. The clear explanation is not performed about what role the general contractor is playing in the construction project to every customer, especially owners from overseas firms and a domestic foreign affiliate with the progress of the globalization.

Two causes can be pointed out to express the difficulty to clarify the business and the role of the general contractors. One is a basic character of building, that is, the order-made system. Even a single building consists with the complex compositions of various materials, equipment, and labors. The other one is the low quality of contract drawings. The responsibility is not necessarily clear from at first concerning the construction condition, the specification, and the role of the general contractor. The design change and the additional work often occur in building projects.

\section{JAPANESE MANAGEMENT SYSTEM}

The industrial structure of Japan is expediently called "Japanese management system". Japanese management system contains a peculiar philosophy. In general, the lifetime employment, the wage constitution, and the trade union organized on a company basis of and seniority are indicated.

In this system, the consensus through the internal memo and pre-arrangement are valued in decision making. It is pointed that there is a social demand that values the community principle behind these characters. Japanese management system was formed at the revival period in postwar days, and became the mainspring of a Japanese economic development from the highly developed economic growth period through the oil crisis. However, the fundamental review is being urged now as the international standard is asked by the development of the globalization. And the maintenance of the promotionby-age system becomes difficult.

\section{FACTS IN JAPANESE CONSTRUCTION INDUSTRY}

\subsection{Outline of the survey}

The facts with "Japanese management system" of the construction industry are taken up in this chapter. In Japanese construction industry, there are facts that show the typical characters of Japanese management system that even if native Japanese people cannot explain the reason. Foreign people might think many of the facts in their surroundings that seem to be difficult to understand. The facts were collected from Japanese architects and engineers who belong to the project management subcommittee in the Architectural Institute of Japan. The following areas are shown in the free formatted questionnaire to find the facts.

- $\quad$ safety and fire precautions

- employee educational system

- cost control

- $\quad$ contract for construction work

- commercial practice and customs

- quality control

- organizations and individuals,

- technology developments

- construction organization

- $\quad$ project procurement

- $\quad$ building sites and its surroundings

\subsection{Result of the survey}

The facts obtained from the survey were categorized with the area of the management. The group of the facts shows a frame of the construction industry, however, it should be noted that they are simply copied from the responders' comments and so they are not well structured and polished.

Project Integration Management

- All things seem good as long as it is "Efficiency priority" in all.

- There is uselessness in each place of the business flow because the re-engineering of the business is not done compared with the process industry, and the cost has disappeared with the bubble. 
- The part of software is immature because priority has been given to the technology development of the structural work method.

Project Scope Management

- There is little consideration of advancing work to the stakeholders of the project (owner, architect, general contractor, and specialist contractor) based on the contract.

- $\quad$ There is little meaning of the contract.

- The content of the contract is not often understood well. Sometimes the stipulation has not been read.

- The range of the responsibility is indistinct in the contract.

- A substantial content of the contract is a drawings and specification (drawings, specifications, estimation condition book, and question and answer book, etc.). Construction is sped up like being vague the content of the contract including the scope of works.

- Everyone tries to complete the project changing neither the amount of money nor the process even if the condition and the content of the contract change during construction.

- The document that is required to make the contract for construction work is vague and indefinite.

- The site staff gives priority to owner's intention rather than considers the stipulation.

- Construction is often started before the construction contract is concluded.

- As for the same business relations, detail of the transaction is different depending on the site and time.

- The range of the contract is different among every project.

- The general contractor should make the working diagram and the detail drawings because design firm does not publish enough amount of detail drawings.

- $\quad$ There are a lot of cases that design tasks are not finished at time of the contract, and so the business in a production design and drawings total chart has entered in the scope of business of the construction contract in the custom. The detailed design and construction are clearly ordered to one business unit in shape of "bridging" in the United States.

- The business (detailed drawings and total chart, etc.) which the designer should originally make is made to be borne responsibility to the general contractor's side because a cheap design fee is allowed to design firm.

- The general contractor executes solutions of pollution problems, the negotiation with the resident and the noise and waste etc., substituting the owner.

- There are a lot of jobs, which are gratuitous, in the engineering done beforehand of procurement.

- Because the consultant market is immature, general contractors are forced to help the jobs in the design stage.

- The administration makes general contractors owe worker's environment and health which main employment should originally assume responsibility. It is pretext of generalization responsibility.

- There are a lot of jobs that is required to do together, like putting things in order etc., besides original work.

- The responsibility division of the general contractor and the specialist contractor is indefinite.
- Work of another occupational category might be executed by a specialist trade.

Project Time Management

- The term of works is observed strictly even if becoming what situation.

- There are a lot of starting constructing beforehand of the contract to observe the demand of the owner (term of works) strictly.

Project Cost Management

- The intention of "rough estimate" or "putting things together" is strong. Not only the manager but also both middle managers and sites engineers deeply have the ideas, for instance, "Only have to gain in the next project though we cannot make a profit in this project", "Even if our design fee is free, we only have to undertake construction. We can recover."

- The price of the material includes various prices like the fixed price, the designers' price, the price for the general contractors, the price for the specialist contractors, and the price published in the handbook. An accurate price is not understood.

- The valorization is based on negotiation. The price making with a high transparency by the bit (tender) cannot be done.

- How much do you discount the amount of money from the estimation you have submitted?

- The amount of money has been estimated considering that traders can be forced to discount the price.

- As the proposal method is not used enough, tenders are on the basis of the amount of the fee.

- The settlement by the bill with long term.

- Consideration concerning designer's function is low, and the dumping of the design fee is daily generated. Therefore, the design fee is general cheap.

- Because the general contractor is holding a lot of sections, indirect expenditure is high.

- The cost control at each various construction is not done, and control as one project balance of accounts matching is always done in Japan.

- The general contractor has an affiliated organization named "XYZ Group" or "XYZ Kyoryokukai". Thus, the organization to which a new trader is not accepted is made, and the price of the union or the stipulated price is set.

Project Quality Management

- The demand standard to the quality is severe.

- The result is not made public to the owner though the general contractor has actually gone in QC etc. Moreover, the owner does not ask to general contractor either.

- It is only a free slip of paper though the inspection book is made for the quality. It is not in time for the term of works if the owner points out. The bar arrangement inspection is executed in the very limit at time to place concrete.

- It is easy to meet a constant standard with the building performance because there is variously group standards.

- Everything is restrained to the specification regulations, though it is truly shifting to the performance regulations. It is thought that the movement standardized at once for Europe and America is remarkable. The United States people make the de facto standard well.

Project Human Resource Management

- The cartel and adhesion (Convoy fleet form rather than the competitive world). 
- It is remarkable that Japanese system often depends on cartel and affiliate. "Whether you are a companion or not?" gives priority in above all.

- The design firm and the trader are respectively in the cooperation mutual trust with government and municipal offices. The government office gives preferential treatment to the person who has results in the long term. But a new office and the trader are not accepted. For example, the officer passes the document to a newcomer without explaining an annoying procedure.

- Organizing horizontal association (academy activity etc.)

- It may be only Japan that the organization like the Architectural Institute of Japan exists all over the country.

- The cooperation of government industries and universities is rare in Japan (especially, in private projects). It is heard that there is often a joint research in Europe and America. Is the reason that there is a mechanism that a joint research is supported in Europe and America?

- The general contractor in Japan has the mechanism that the subcontractor cannot tender by open.

- There are a lot of capitals of the general contractor and numbers of employees, and the general contractor has the design firm and the research and development department.

- $\quad$ Long-term mutual trust of the person concerned is the most important. The intervention of the third person like the lawyer and mediation in the court, etc. is avoided as much as possible.

- There is no culture by which the lawsuit is valued in Japan. Therefore, when the problem occurs, the procedure of a correct indictment is not taken. A lot of complaints that do not step on the procedure are generated. People emotionally solve the problem because they do not obtain a formal judgment. Even if the tiger pull is solved, root of evil often remains.

- Because human resource flows violently in Europe and America, the engineer coming from general contractor might become a project manager on the owner side. Thus, management is used as general knowledge. However, the management style is different in each firm in Japan because of the lifetime employment. The exchange among them is little.

- To secure the construction quality, and to adjust the labor, the affiliated multi-story subcontract structure is possessed.

- The specialist contractor is not regarded as an equal relation to the general contractor.

- It is necessary to submit the specialist contractor to the general contractor absolutely. Otherwise, the following job does not exist in the future.

- The general contractor in Japan historically assumes carpenter's chief to be a starting point, and has the character of the specialist contractor of the structural works and the character of the general contractor of the integrator of the project. Therefore, construction is managed centering on the structural works.

- The general contractor is doing the care of the worker though it is a task of the specialist contractor.

- Engineer and craftsman's function and roles are vague in Japan, and only the experience is evaluated. Therefore, the union might not be able to be organized.

- The organization of cooperated union of the profession kind has little power

- The multi trade worker and the all-round worker can be adopted.

- The horizontal development can be arbitrarily done.

- Vertical development can be arbitrarily done.

- Workers' systematic base is weak They are based on a daily employment with the relation of boss and the follower.

- The Japanese worries about neither going to work in the early morning nor the overtime work so much. They do not complain. It seems that it has the cause in undertaking contract.

- The workers in Japan do not want to take vacation, because it is not a monthly salary plan.

- $\quad$ There seem to be a lot of joint ventures.

- The project is managed by the formation of the project team, which assumes the project manager to be length in the functional organization. Therefore, the whereabouts of an inclusive responsibility of the project becomes indefinite.

- The consensus in the each level in the organizations is required.

- Everyone works seeing the circumference. Someone pretends to work. There are some people staying the company till late doing the small talk although they do not have tasks.

- $\quad$ "There's safety in numbers."

- The worker in Japan has a strong loyal core as a family in the firm.

- $\quad$ "A tall tree catches much wind." And everyone hits the tree..

- The policy is not systematized and is different according to the favor of an each boss.

- It is difficult to warn one's superior person because it is seniority. Everyone is not accustomed to the direction to a senior person. Oppositely, the instruction of a person younger is not obediently accepted.

- There is a trend of the age by which generalist is valued from the specialist.

- There is a system in the enterprises of training to the worker from a long-term aspect, the reshuffle, and the promotion, etc. A skill improvement of the worker been brought by this habitual practice. As a result, the quality is constantly improved, there is a innovation in an existing product and the process, and skill by the experience is remarkable.

- The general contractor is rapidly maintaining a systematic employee education in Japan. Still, it is the empiricism On Job Training. The net profit step is not taught though the business of every day is executed for the present by a free style.

- This is an education of the business required to work in the general contractor for the long term rather than the education for the field management.

- The premeditated education is executed to the employee on the assumption of long-term employment.

- The employee education required lifetime employment, and located as site OJT in a wideranging, long-term career path.

- An empiricism education is a center from the standardization of the business.

- The means with the effect to confirm field workers' skill is few. 
- Across-the-board recognition of an actually career advancement does not exist in Japan except the qualification of the architect license etc.

- Because it is formal, and the necessity is not understood. Those who attend the lecture attend only because others attend that lecture.

Project Communications Management

- Harmony as the group and the team is attached to importance in Japan rather than presence as an individual.

- The unit of the organization in a project is not an individual but all groups. Therefore, the consensus of the entire organization is valued.

- Giving priority to consensus more than the discussions is a style of Japan.

- All members are aiming to be brainwashed to the rule of the organization.

- Because everyone does not have his/her original opinion or idea, he/she tunes to the others, the suppliers, and the general contractor quite soon.

- $\quad$ "I also agree with you if Ms. MM agrees with you."

- The Japanese is good at group activity. For instance, they make arrangements without complaining <morning gathering>, regular meeting, cleaning together, and do the intimacy association (barbecue party), etc.

- There is a morning gathering on the site, and all workers are made to attend every morning. The journalist of the BBC television who had come to Japan saw it from the hotel, and he came to cover being surprised.

- When the problem is caused, it is often entrusted to the conference and negotiation.

- A daily conference and the arrangement made a mannerism are abundant. The general contractor also forces the same thing on the specialist contractors though they complain that the fee is not paid to service. It is described clearly that there is a meeting how many times a week in the estimation condition book on the United States.

- The business is accomplished by each department separated strictly both in the public office and private firms. Therefore, the loss and the difference are generated easily in the transmission of information.

Project Risk Management

- All the judgments are based on confidence, and there is no idea of the risk.

- Few of own responsibility

- The restriction called application, the written report, permission, and authorization is abundant.

- Many of guidance matter of the administration

- There are a lot of recognition matters at Building Center of Japan.

- It takes time for the judgment to have it admitted even if a new technology is developed. The technology is not admitted until the scholars make the opinion "It is absolutely safe". Oppositely, if big Professor guarantees it, it is admitted easily.

- As for all of QCDSE, the responsibility of the general contractor is heavier than the one of those in the nations of Europe and America.

- Many of safety and fire precautions on the construction site are in the range of the responsibility of the general contractor in Japan.

- The safety facilities to excessive are prepared in Japan compared with Europe and America.

- There is a morning gathering on the site, and all workers are made to attend every morning. It is very few that the individual assumes the responsibility when the accident occurs on the site. It often becomes the responsibility of the general contractor. As a result, the site work cannot be continued. The work will be commanded to stop by the Ministry of Labor. The term of works cannot be kept. Therefore, the morning gathering is an efficient method to gather everyone to explain the safety notes. The United States is a society of the idea "I defend myself". Japan is the one "The company and the country will defend us". However, even if the emergency is generated, neither the company nor the government actually defends the individual. The experience due to the disaster such as earthquake shows that such a system does not exists.

- An insurance company directly related to the problems of the death, injury, and closed amends, etc. is indifferent to them.

- The effect of a new technology cannot be confirmed before the owner buys the product.

- Stinginess is applied to a new developed technology before executed. Nothing is made for myself and only stinginess is said. Spurious improvement and treatment.

- There is no system that supplements a skill insufficient on the owner side.

- Existence of Mafia concerning illegal disposal of waste or underground money.

- People in the vicinity try to exclude a new project without the reason. On the other hand, the general contractor ambiguously solves the trouble by money.

- $\quad$ "All are good as long as I can avoid the trouble from the project."

- Those who find the fault of the general contractor during construction term, and later force the $\mathrm{GC}$ to repair their wall in their place or to adjust their fittings.

- $\quad$ "Only I am safe."

- There is no consideration of defending one's safety by himself/herself. If a big accident happens, the responsibility is imputed to the others, the company, and the government.

Project Procurement Management

- As Japanese group mentality of the enterprise is strong, general contractors are monotony, lacking personality.

- $\quad$ General contractors try to offer full set of services such as the programming, design of the upstream, operations of the downstream.

- Joint development in industry group.

- Construction industry activity of cartel based on cooperation in industry

- The public office and the owner domineer oddly. And they are entertained oddly courteously.

- There is cooperative relationship of politicians, government, industries, and universities that is community of common interest.

- In the field of engineering works and nuclear power, there are a lot of supplementary research and development of the government.

- The possession of the stock each other and the affiliate are composed to form the strong stockholder. The procurement of the project and the materials are closed within this circle.

- Pyramidal structure of construction industry

- The variation of the procurement method is limited. 
- A lot of general contractors in Japan contract out structural works by detailed division of labor employment. They do only management in the equipment works. The market of the general contractor of the total structural works or the general contractor of the total finishing works is undeveloped.

- $\quad$ Every construction contract is in "Turn-Key" style.

- Long-term mutual trust with the customer is valued. Lending and borrowing of jobs.

- $\quad$ "Mutual trust" between the enterprises has a big impact more than the contract.

- There are a lot of projects specially nominated.

- A lot of private projects are contracted with negotiation based on long-term business relations. The special nomination increases inevitably.

- $\quad$ This is the world of "Judo" wrestling, that is, "Long term association" can be a key word.

- The customer can do nothing but contract on supplier's ring.

- The judgment standard on the owner side is based on the assumes "Wrong experience" and "Wrong historical performance".

- The client in Japan strongly has the idea of lump sum or turn key, and they seldom consider to confirm during construction period. Recognition to the in-process check is thin to a contractor.

- $\quad$ "Lump-Sum" is allowed even if contents are not understood.

- $\quad$ Everyone asks "How much in all?" But the contents are still opaque.

- Construction works are occasionally different from the content of the contract. There are many works and services that are asked by the owner "Please do this one while you are at it....".

- Guarantee is contracted out to the specialist contractors, so the negotiation is not practical. The condition of the contract is vaguer than that of Europe and America where there are a lot of lawsuits.

- The vicinity resident does not know who is the specialist contractor, even if the name of they know the name of the general contractor.

- Relation between small-scale engineering firm and construction materials maker shows a typical character of Japanese system. Moreover, the relation in component development between prefab makers and construction materials makers are another feature.

- The power of the outsourcing is weak to the construction industry of Japan. Because the border bounds, everything is being actively procured from the foreign country in each country of Europe.

- Existence of public investment which is a tool of business recovery.

- The government does not have the will to bring up small business only by defending. Therefore, the action of the government does not lead to the morality improvement as the entire industry.

\section{CONCLUSIONS}

The purpose of this research is to enable a logical explanation to the customers about the feature of management and procurement of Japanese construction industry, especially the responsibility and role of general contractors. The facts that typically show the characteristics of Japanese system were collected through the survey. As a result the facts can be summarized as follows:

1. Mutual trust between the owner and general contractor is very valued. In the long-term and mutual trust, the owner positively evaluates the managerial technique of the general contractor and the quality. It also neglects equality between them concerning the cost and the duration of construction works.

2. There is little consideration to the affiliated system and the risk. This influences various problems of the construction industry.

3. The self-help is necessary for the improvement of the situation of the specialist contractors.

4. The high cost of the project delivery is caused by the heavy and complicated organization of the general contractor.

In this paper, the survey of the facts is focused, and so its analysis and discussion should be continued in quantitative way. The facts should be structured to find the key to solve the framed problem in the next step of the research. The conditions to which the facts are subjective should be shown such as the scale of the market, the scope of the project, commercial practices, and so on.

\section{Acknowledgments}

This paper was written under the cooperation of the Accountability Working Group of the Project Management Subcommittee in the Architectural Institute of Japan. This study is funded by "Grant-inAid for International Scientific Research (Joint Research)" from The Ministry of Education, Science, Sports and Culture, JAPAN.

\section{REFERENCES}

[1] T. Kaneta, et al. "Accountability of Japanese Construction Industry" Proceedings of the $1^{\text {st }}$ Workshop on Project Management, Architectural Institute of Japan, pp.9-26, 1999.

[2] T. Kaneta, et al. "Japanese System in the Field of Construction Industry- Part 1: Facts and Characters Exclusive to Japanese System." Proceedings of the $16^{\text {th }}$ Symposium on Organization and Management of Building Construction, Architectural Institute of Japan, 2000, (Accepted).

[3] T. Kaneta and S. Furusaka, "The Facts Peculiar in Japanese Construction Industry" Summaries of Technical Papers of Annual Meeting, Architectural Institute of Japan, 2000, (Accepted). 